\title{
"Sempre Haverá o Melhor e o Pior":1 controvérsias, criatividade e enquadramentos INTERPRETATIVOS EM TORNO DAS ESTATÍSTICAS DE PRODUTIVIDADE COMPARADA DOS ATORES E DAS ORGANIZAÇÕES JUDICIÁRIAS NO BRASIL ${ }^{2,3}$
}

Maricilene Isaira Baia do Nascimento ${ }^{4}$

Rebecca Neaera Abers ${ }^{5}$

\section{INTRODUÇC̃̃O}

"[Tribunal de Justiça do Estado da Bahia] TJBA é o 7o pior em ranking do CNJ" (Nascimento, 2016), anunciou o jornal Metro 1, em outubro de 2016. No corpo da matéria, a notícia destacou que "Quando o assunto é produtividade, o TJBA continua deixando a desejar. É o que indicam os dados do Conselho Nacional de Justiça (CNJ). (...) o estado amarga a 7ª colocaçáo" (Nascimento, 2016). Procurado pelo jornal, o presidente da Associação dos Magistrados da Bahia mobilizou estatísticas também publicadas pelo CNJ para construir a explicação favorável de que, apesar da baixa colocação, "O juiz [baiano] mata um leão por dia" (Nascimento, 2016). Este é um caso que exemplifica o desconforto que os atores do Poder Judiciário vivenciam a cada ano, quando o Relatório Justiça em Números do CNJ publica, entre outras estatísticas, o ranking do Índice de Produtividade Comparada da Justiça (IPC-Jus).

As estatísticas anuais do Poder Judiciário são publicadas, desde 2004 (ano-base 2003), pelo Relatório Justiça em Números que, segundo o CNJ, “(...) divulga a realidade dos tribunais brasileiros, com muitos detalhamentos da estrutura e litigiosidade, além dos indicadores e das análises essenciais para subsidiar a gestáo judiciária brasileira” ${ }^{6}$ Esse relatório é coordenado e desenvolvido pelo Departamento de Pesquisas Judiciárias (DPJ) do CNJ, e o IPC-Jus, inovaçáo estatística lançada no relatório de 2012 (ano base 2011), é um ranking criado a partir de uma técnica estatística comparativa não paramétrica de eficiência produtiva chamada data envelopment analysis (DEA análise envoltória de dados). Esse indicador tornou-se a "menina dos olhos" dos envolvidos e afetados nos/pelos processos judiciais, além dos da mídia, porque, ao resumir o cenário de produtividade processual relativa dos tribunais brasileiros, é a referência desses atores de interesse para identificar qual o melhor e o pior tribunal no país.

Neste artigo, objetivamos identificar as estratégias de formação de interpretaçôes favoráveis criadas para contornar evidências científicas, em especial a evidência estatística. Especificamente, identificaremos as estratégias de formação de interpretaçôes favoráveis em contexto no qual a evidência estatística problematiza a credibilidade social dos atores e das instituiçóes das quais são

\footnotetext{
1. Parte da fala do entrevistado 2, servidor do TJPA, da pesquisa.

2. DOI: http://dx.doi.org/10.38116/bapi24art12

3. As autoras agradecem os valiosos comentários e sugestões das pareceristas deste artigo As sugestões e observações somaram muito para a qualidade da versão final. Quaisquer imperfeições são de nossa própria responsabilidade.

4. Doutoranda em ciência política no Instituto de Ciência Política da Universidade de Brasília (IPOL/UnB). Pesquisadora bolsista do Programa de Pesquisa para o Desenvolvimento Nacional (PNPD) na Diretoria de Estudos e Políticas do Estado, das Instituições e da Democracia (Diest) do Ipea. 5. Professora associada do IPOL/UnB.

6. Disponível em: <https://www.cnj.jus.br/pesquisas-judiciarias/justica-em-numeros/>.
} 
parte, cuja técnica comparativa a partir da qual é desenvolvida necessariamente estabelece quem é o pior e o melhor. Além disso, em situação na qual os atores são comparados por técnica que gere desigualdades necessárias, objetivamos também identificar as controvérsias presentes em torno dos critérios de comparação desse tipo de estatística.

Para identificar a ação criativa de formar interpretaçóes favoráveis em contexto no qual evidências estatísticas problematizam a credibilidade socioinstitucional dos atores, argumentaremos que essas evidências ganham diferentes interpretaçóes, a depender do contexto no qual se encontram e a depender da habilidade dos atores em empreender a projeção de diferentes interpretaçóes a partir delas. Mais precisamente, argumentaremos que, em cenários de comparação nos quais alguém necessariamente perde e nos quais a ação do outro a quem se é comparado é imprevisível, os resultados dessa comparação ganham diferentes interpretaçóes, a depender da habilidade dos atores afetados em recombinar os elementos constituintes da evidência, a fim de mitigar perdas de imagem socioinstitucional.

A tese a ser trabalhada neste texto é que o uso simbólico das estatísticas oportuniza que os atores criem novas posiçôes e novas interpretaçóes de si, em um amplo contexto socio-organizacional. Este argumento coloca em cheque a premissa de que o uso simbólico dos resultados de pesquisa envolve quase sempre legitimação e sustentação de posiçóes predeterminadas, ou seja, envolve legitimar e sustentar interesses já estabelecidos (Beyer, 1997). O uso simbólico de pesquisas também envolve ação estratégica intersubjetiva, ou seja, envolve responder à criação de enquadramentos sociais que uns determinam para outros, elaborando novos enquadres que consideram mais apropriados. O uso de evidências está imerso em relações de poder e há possibilidades de construção de múltiplas interpretaçôes (Veselý, Ochrana e Nekola, 2018).

Como estratégia metodológica, recorremos às repercussões do IPC-Jus no âmbito da Justiça Estadual (Tribunais de Justiça - TJs). A Justiça Estadual é o segmento do Poder Judiciário brasileiro responsável por $80 \%$ dos processos judiciais no país. Pelo tamanho expressivo de litigiosidade, o IPC-Jus potencialmente repercute de modo controverso, principalmente pela desigualdade estrutural das quais os tribunais dispóem, resultante, entre outros aspectos, da submissão à legislação e ao orçamento das respectivas Unidades da Federação a que pertencem. Os dados empíricos são coletados de noticiários institucionais e midiáticos, além de entrevistas com servidores representantes de TJs e de entrevistas com servidores que já fizeram parte do CNJ. ${ }^{7}$

Além desta introdução, as seções que seguem expõem a mobilização teórica que subsidiará a relação entre evidência, ação criativa e habilidosa dos atores que, a partir dos casos trabalhados, possibilitará a criação de um frame explicativo do processo de criação de novas interpretaçóes consideradas favoráveis. As consideraçóes finais destacam os principais achados desta pesquisa.

\section{CONTROVÉRSIAS, CRIATIVIDADE E ENQUADRAMENTO INTERPRETATIVO EM TORNO DE ESTATÍSTICAS}

No debate sobre e no fazer de políticas, conforme argumenta Pinheiro (2019, p. 29), "evidências são importantes, porém não decisivas", principalmente porque o poder da evidência pode variar segundo seu contexto de uso e a instituição que a produz. É um argumento crescente entre os estudiosos mais

7. Nesta fase da pesquisa, foram inseridas apenas entrevistas com servidores técnicos, os quais apontam, do ponto de vista técnico-político, onde estão situadas as controvérsias da formação do IPC-Jus. Narrativas de juízes foram coletadas de matérias institucionais de TJs. 
críticos que "o uso que se fizer das evidências - nos contextos e nos propósitos determinados - é que indicará o que elas realmente são” (op. cit., p. 36).

Na relação entre estatística e politics, Haggerty (2002) destacou vários potenciais de uso desse tipo de evidência. Entre eles, está o alocativo de recursos (materiais e simbólicos) que podem favorecer ou arruinar political fortunes de indivíduos e organizações: "quais números são produzidos, de que maneira, e como eles são comunicados pode estruturar como os grupos de ação política entendem os problemas que suas localidades enfrentam" (Haggerty, 2002, p. 92). Sendo assim, argumenta que a política administrativa de estatística diz respeito à manipulaçáo prospectiva de um arranjo de dados coletados para subsidiar interesses políticos e institucionais.

Mais especificamente argumenta Haggerty, que, no favorecimento ou ruína de political fortunes de indivíduos e organizações a partir do entrelaçamento entre quais números produzir, a maneira de produzi-los e como comunica-los, "A dimensão política administrativa mais contenciosa e recorrente está relacionada à questão da definição operacional, ou classificação” (Haggerty, 2002, p. 92). Classificar atores pode mostrar-se muito controverso, porque as instituiçóes estatísticas os tratam como membros de grupos abstratos em vez de indivíduos com identidades, histórias e motivaçóes únicas. E esse ethos classificatório da estatística confere aos knowledgeable actors (atores habilidosos) a oportunidade de criação e apreensão de novas identidades de si, a partir das novas interpretaçóes que desenvolvem de si mesmos e dos outros.

A estatística pode ser politicamente muito eficaz em atingir a criação de identidades e frames culturais para possibilitar mudanças de si e de uma cadeia longa de atores, porque possibilita a atores e agências governamentais a habilidade de "agir de longe", de permitir representaçôes de pessoas e lugares para viajar grandes distâncias a locais onde elas são frequentemente combinadas com outros números, concorda Haggerty (2002, p. 98), a partir de argumentos de Latour (1987).

No entanto, para dar sentido ao uso de estatísticas, a criação da narrativa e a qualidade da narrativa são cruciais porque os "números nunca falam por eles mesmos" (Haggerty, 2002, p. 95). O uso retórico de estatísticas muitas vezes pode performar um tipo de mágica social, identifica Haggerty, por dar aos clamores políticos um grau de urgência e um "ar" de verdade científica, não sendo um instrumento de "mero suporte": "estatísticas proveem idioma científico para demonstrar que um problema social tem importância” (Haggerty, 2002, p. 95). Aliás, uma das características políticas da estatística repousa na retórica, que é usar a habilidade de "invocar" a terminologia científica para fazer "coisas mágicas", tais como "viajar através do tempo e criar pessoas virtuais", principalmente porque "o discurso contemporâneo tem uma dinâmica comparável. [E] envolve 'fazer coisas' com números, com estatística sendo usada como uma ferramenta persuasiva para avançar causas políticas" (Haggerty, 2002, p. 95).

Mas como os atores usam as estatísticas para atingir os seus propósitos? Por quais mecanismos? Quais características das evidências estatísticas permitem que os atores consigam criar novas identidades e produzam novas interpretações de si? Como se dá a formação de narrativas para fazer "coisas mágicas" e criar pessoas, identidades e interpretaçôes?

Um caminho propositivo para alcançar as respostas destas perguntas é partir da premissa de que evidências estatísticas são instrumentos para enquadramentos interpretativos, ferramentas que podem ser usadas pelos atores para intencionalmente criar moldes interpretativos para projetar imagens 
socioinstitucionais positivas e/ou negativas de si e dos outros. A noção de enquadramento tem raízes teórico-conceituais na psicologia de Gregory Bateson e na sociologia de Erving Goffman; Mendonça e Simóes (2012, p. 191) destacam que a definição de enquadre ou enquadramento consolidou-se como sendo os princípios organizativos que governam acontecimentos sociais e a interação subjetiva neles. São esses princípios organizativos que definem a situação na qual os sujeitos se encontram.

No processo de enquadramento, Silva, Cotanda e Pereira (2017) destacam que, especialmente para Goffman, a riqueza das situaçóes sociais produz muitas possibilidades de interpretaçáo; por isso, há maneiras diferentes de enquadramento. Entre elas, estão as fabricações, que são "esforços intencionais de atores sociais para produção de definiçóes de situaçóes vistas como inapropriadas pelos próprios atores" (Silva, Cotanda e Pereira, 2017, p. 148). Esta maneira transformativa de enquadramento pressupóe que atores sociais dotados de agência e reflexividade podem, a depender da situação na qual se encontram, "modificar molduras interpretativas de forma a classificar as situaçóes vividas de acordo com seus interesses nas interaçóes em curso" (op. cit., p. 149).

No campo da análise de conteúdo discursivo, Mendonça e Simóes (2012) destacam que a noção de enquadramento é operacionalizada a partir do propósito em compreender o modo como discursos estabelecem molduras de sentido, além de buscar a pensar a maneira pela qual o conteúdo discursivo "cria um contexto de sentido, convocando os interlocutores a seguir certa trilha interpretativa" (Mendonça e Simóes, 2012, p. 193). Nesse campo de análise, Entman (1993) argumentou que framing essencialmente envolve a seleção de aspectos da realidade percebida para salientá-la em um texto comunicativo: que significa tornar um pedaço de informação mais noticiável, significativo, ou memorável para a audiência.

Em contexto no qual os atores necessitam projetar interpretações positivas de si quando alcançam posiçóes desfavoráveis em rankings estatísticos, argumentamos que a possibilidade de fazer "coisas mágicas" com as evidências estatísticas está na condição de elas mesmas, as estatísticas, serem internamente diversas, ou seja, na possibilidade de existir uma diversidade de elementos constituindo-as a partir da qual os atores podem criar trilhas interpretativas de seu interesse. Apesar de náo tratarmos evidências estatísticas como instituiçóes, esse insight é inspirado na proposta pragmatista de Berk e Galvan (2013, p. 32) de que instituições são sempre internamente diversas "porque são compostas de um número indefinido de características, cujo relacionamento está sempre sendo renegociado". E essa diversidade, argumentam, permite que os atores recombinem os elementos que as constituem para reinterpretarem a sua posição (muitas vezes desfavorável) em uma arena institucional.

Oportunamente, quando alcançam posiçóes desfavoráveis em rankings, os atores precisam criar posiçóes favoráveis a partir dos elementos (ou de outros contextualmente coerentes), nesse caso estatísticos, que os desfavoreceram, ora abandonando, ora recombinando alguns desses elementos, para proporem trilhas interpretativas positivas de si. A esta ação criativa propomos chamar de enquadramento de reposicionamento. Reposicionamento é um conceito criado por Berk e Galvan, no contexto das relaçôes institucionais, que se refere a quando os atores abandonam alguns papéis familiares e relaçóes de poder para agir como se tivessem mais (ou menos) habilidades, autoridade e impacto do que se supóe possuírem - um atalho conceitual a partir do qual nos inspiramos também para o contexto deste artigo.

No entanto, não basta apenas afirmar que as estatísticas sejam internamente diversas e que, por meio de enquadramentos reposicionais, os atores criam trilhas que projetam interpretaçóes positivas 
de si. Argumentamos que os atores precisam dispor da habilidade em perceber essa diversidade e a habilidade de saber criar recombinações, de modo a projetarem tais interpretaçóes. Esta é uma habilidade socialmente estratégica, que envolve a capacidade dos atores de projetarem interpretaçôes de si em resposta ao e/ou considerando elementos de framing que outros já criaram, obedecendo a uma margem de coerência e contextualização, para dizerem o que eles são a partir do que os outros disseram o que eles deveriam ser. Este último argumento é inspirado na proposta de Neil Fligstein (2001), que relaciona a habilidade socialmente estratégica à capacidade de atores de motivarem grupos díspares a cooperar, inclusive manobrando atores poderosos, a partir da criação de identidades e frames culturais, principalmente na criação de significados que atingem uma longa cadeia de atores. Para isso, em suma, Fligstein refere-se à capacidade de dizer o que os outros são e o que eles querem.

$\mathrm{Na}$ próxima seção, trabalharemos os argumentos e os conceitos mobilizados para explicar o processo a partir do qual os atores criam novas posições para projetarem interpretaçóes favoráveis de si, especialmente em situaçóes nas quais sua imagem socioinstitucional se encontra em situaçóes desfavoráveis por ranqueamentos estatísticos que consideram controversos.

\section{DAS CONTROVÉRSIAS AO REPOSICIONAMENTO CRIATIVO: A REPERCUSSÃO DISCURSIVA DAS ESTATÍSTICAS DE PRODUTIVIDADE DOS ATORES E DAS ORGANIZAÇÕES JUDICIÁRIAS NO BRASIL}

\subsection{As controvérsias em torno do IPC-Jus na visão de atores de Tribunais de Justiça}

O IPC-Jus foi lançado no Relatório Justiça em Números: 2013 - ano-base 2012, sob o argumento do avanço e aperfeiçoamento das análises do $\mathrm{CNJ}$ em níveis mais complexos dos dados enviados pelos tribunais, "em vez de exposiçóes [estatisticamente] descritivas" (CNJ, 2013, p. 18). Por motivo de viabilidade estatística (comparada), tribunais estaduais, federais e do trabalho têm seus resultados "resumidos" pela técnica DEA. É uma técnica de análise multivariada que objetiva construir um indicador sobre o quanto se produz (outputs) com o quantitativo de recurso disponível (inputs). É uma técnica de eficiência. O propósito era "fornecer dados quantitativos sobre o quanto cada tribunal deve aumentar na produtividade para alcançar a fronteira de produção, considerando-se os recursos de que cada um dispóe, além de se estabelecer um indicador de avaliação para cada unidade” (CNJ, 2013, p. 18-19).

Nos termos que constam no Relatório Justiça em Números: 2019 (CNJ, 2019, p. 182), o IPC-Jus "é uma medida que busca resumir a produtividade e a eficiência relativa dos tribunais em um escore único, ao comparar a eficiência otimizada com a aferida em cada unidade judiciária"; "O comparativo é produzido com base no Índice de Produtividade dos Magistrados (IPM), no Índice de Produtividade dos Servidores (IPS), na Despesa Total do Tribunal e na Taxa de Congestionamento (TC)" ${ }^{8}$

O IPC-Jus não é qualquer ranking. É um índice formado por uma técnica estatística que, pela sua natureza não paramétrica, não desenvolve um ranking com critérios preestabelecidos. Para a formação do ranking, cria-se um parâmetro a partir de comparação: os dados de todos os tribunais são "rodados" pela técnica DEA, e, dessa comparação, conhece-se qual foi o melhor tribunal (ver Jordá,

8. Conforme é descrito mais detalhadamente no relatório (CNJ, 2019, p. 182): "Esse método permite comparações entre tribunais do mesmo ramo de justiça, independentemente do porte, pois considera o que foi produzido a partir dos recursos ou insumos disponíveis para cada tribunal. A respeito dos insumos, o índice agrega informações de litigiosidade - número de processos que tramitaram no período (excluídos os processos suspensos, sobrestados, em arquivo provisório e de execuções fiscais e penais), dados sobre recursos humanos (magistrados, servidores efetivos, comissionados e ingressados por meio de requisição ou cessão) e sobre recursos financeiros (despesa total da Justiça excluídas as despesas com inativos e com projetos de construção e obras). 0 índice avalia também a quantidade de processos baixados, excluídos os processos de execuções fiscais e penais". 
Cascajo e Monzón, 2012). Ele é considerado o melhor no indicador, submetendo os outros resultados das outras unidades ao resultado dele. Uma entrevistada chega a interpretar que o "IPC-Jus não é um ranking [em termos mais convencionais], ele é pura comparação" (entrevistada 1, ex-servidora do DPJ/CNJ).

Ao que parecia na descrição do relatório, era apenas um resumo de dados e formação de eficiência relativa em score. No entanto, o que não fica, de maneira direta e muito explícita, é: alguém sempre se "dará bem" e "sempre se dará mal", necessariamente. Não é um simples resumo dos dados, é o caminho para um propósito maior, segundo um entrevistado da pesquisa: "quando questionávamos sobre a aplicação dessa técnica, o argumento deles era de que os tribunais seriam estimulados a se nivelarem [em modernização administrativa]" (entrevistado 2, servidor do Tribunal de Justiça do Estado do Pará - TJPA). Ao que indica, o IPC-Jus era um estimulante de competição entre os tribunais, no sentido de que permitia ao CNJ conseguir agir de longe: "Eles são muito inteligentes [o CNJ]. Essa estratégia de um olhar para o outro diminui muito o trabalho deles. Eles não precisam dizer nada. É só olhar para o indicador. (...) é só olhar para o outro [tribunal]" (entrevistado 3, servidor do Tribunal de Justiça do Estado do Amapá - TJAP).

Entre os entrevistados da pesquisa, o entrevistado 2 resume bem toda a controvérsia gerada no âmbito da Justiça Estadual. Segundo ele, é uma estatística muito perversa, porque sempre haverá o melhor e o pior:

[eles] pegam as variáveis, que são 4, né? Deixa eu ver... [consulta o relatório] (...) Índice de Produtividade dos Magistrados, dos servidores, despesa total e taxa de congestionamento. São essas variáveis. Juntou aqui para calcular. Aí ele calculou e aquele cara vira referência. Ele é o sarrafo. O melhor é o sarrafo. Agora todo mundo vai ser comparado com ele. Se o sarrafo traduzir esse número em 2 metros, tudo isso aqui, todo mundo que chegar em 2 metros é 100\%, e, abaixo disso, vem proporcionalmente fazendo a continha: "olha, eu cheguei em 1,90m". Então, quanto é 1,90 ? É... 95\% ... ok... e agora... [em tom de como se classifica]. É mais ou menos isso que se faz no IPC-Jus. Então, ano a ano, o sarrafo vai dançando. Eu náo posso dizer que o meu $100 \%$ de hoje é igual ao $100 \%$ do ano anterior. (...) Sempre vai ter o pior e o melhor. (...) Boa parte dos indicadores faz essa relação comparativa. Eu posso ser bom, mas se eu for bom abaixo da mediana, eu náo vou pontuar ou vou ganhar menos ponto (entrevistado 2, servidor do TJPA).

Outro detalhe instigante destacado pelo mesmo entrevistado diz respeito à imprevisibilidade de cálculo futuro e ao equívoco em analisarem os resultados de modo longitudinal (através do tempo). Imprevisibilidade, porque é um indicador relativo, de resultado comparado, e, portanto, precisar-se-ia saber dos resultados dos outros tribunais, quase que em tempo real: "para subir, temos que torcer para que o outro desça. (...) Não adianta eu trabalhar muito, se o outro trabalhar mais que eu, meu esforço não vai valer nada" (entrevistado 2, servidor do TJPA). E equívoco longitudinal, porque a comparação é feita a cada ano entre os tribunais a partir dos esforços realizados naquele ano, e, como muda o "sarrafo", o significado de cada resultado muda: "Eu náo sei dizer se o meu $57 \%$ de hoje é melhor ou pior que o meu $56 \%$ de ontem. Talvez ' 56 ' seja melhor que ' 57 ', mas eu nunca vou saber" (entrevistado 2, servidor do TJPA).

Na opinião de outro entrevistado (entrevistado 4, ex-servidor do Departamento de Gestão Estratégica/CNJ), a escolha das variáveis foi feita de modo a "colocar 'os grandes' lá em cima. (...) 
se eu mudar as variáveis, os critérios de avaliação, talvez o último colocado venha a ser o primeiro. Esse não deveria ser o critério. (...) o sujeito que fez isso, foi um sujeito muito esperto”.

\subsection{Contornando posições desfavoráveis em meio às controvérsias: criando outras posições e outras interpretações}

As repercussões do IPC-Jus nos meios de comunicação requereram muita criatividade argumentativa dos atores da Justiça Estadual. Segundo o entrevistado 5 (servidor da área de planejamento do Tribunal de Justiça do Estado do Ceará - TJCE), "quando sai [o relatório] a imprensa explora muito. (...) provavelmente a gente vai ser chamado para explicar o porquê de $18^{\circ}$ e não o 17으, 15o ou 1”. Sobre isso, o entrevistado 4 relatou que os resultados geram muitos desconfortos aos presidentes dos tribunais, e que é momento de muito constrangimento quando atingem posiçóes desfavoráveis no ranking, principalmente diante dos seus pares. Em uma determinada situação, na qual um determinado tribunal alcançou posição desfavorável no IPC-Jus, o entrevistado narra que o magistrado presidente daquele tribunal o chamou e perguntou: "O que eu tenho de fazer? Eu não aguento mais passar vergonha”.

Conforme relatado pelo entrevistado 5, um dos desconfortos institucionais está em construir explicaçóes que sejam favoráveis quando se alcançam baixas posiçóes no ranking de produtividade, principalmente por conta das difusóes pela mídia. Entre os títulos de notícias sobre posiçóes desfavoráveis no IPC-Jus estão: "Magistrados da Paraíba têm o pior índice de produtividade do Brasil", "[Tribunal de Justiça do Estado da Paraíba] TJPB tem 3o pior índice de produtividade entre os tribunais estaduais do país", “TJBA é o 7o pior em ranking do CNJ”, "TJCE tem pior índice de produtividade do país", "[Tribunal de Justiça do Estado do Rio Grande do Norte] TJRN é o 3o tribunal mais caro e o $3^{\circ}$ menos eficiente de pequeno porte", "Piauí tem terceiro pior desempenho entre os tribunais estaduais no Brasil, diz CNJ", "[Tribunal de Justiça do Estado de São Paulo] TJSP continua sendo maior do país, mas tribunal do Rio é o mais eficiente, diz CNJ", "TJCE deixa de ser o pior em produtividade do Brasil”.

A depender de como os atores organizam a comparação dos indicadores, os resultados podem se tornar mais dramáticos do que realmente aparentam ser. $\mathrm{O}$ trecho da reportagem do Jornal da Paraíba sobre os desempenhos do TJPB no Relatório Justiça em Números: 2019 é um exemplo dessa estratégia, muito usada no âmbito da mídia, quando se tenta chamar a atenção para uma situação apresentada.

O TJPB obteve índice 858 no IPM, quatro vezes menos do que o [Tribunal de Justiça do Estado do Rio de Janeiro] TJRJ, que obteve IPM de 3.339, o que, segundo o relatório, representa uma diferença de 2.511 casos baixados por magistrado. A média brasileira é de 1.897 . Já em relação ao IPS, os servidores atingiram 88, enquanto o primeiro colocado nacional ficou com índice de $228 .{ }^{9}$

Os indicadores do Relatório Justiça em Números são calculados por “porte”, por tamanho do tribunal, na justificativa de comparação mais justa. Há três grupos de tribunais: de grande, médio e pequeno porte. Então, como o IPC-Jus é gerado por porte, torna-se equívoco, de alguma forma, comparar tribunais de portes diferentes. O TJRJ é um tribunal de grande porte e o TJPB, de pequeno. Portanto, é equivocada a comparação feita pelo jornal, mas isso tornou a situação do TJPB muito pior do que se houvesse comparado com outro do seu porte. Essa estratégia de recombinação tornou mais dramático o significado de pior.

9. Disponível em: <https://www.jornaldaparaiba.com.br/politica/magistrados-da-paraiba-tem-o-pior-indice-de-produtividade-do-brasil-segundo-cnj.html>. 
O mesmo ocorreu no caso do TJCE, com uma diferença. O jornal Diário do Nordeste, além de comparar os resultados do Relatório de 2018 a partir da diferença de desempenho desse tribunal com o de melhor desempenho na categoria de grande porte, intitulou a notícia sobre a produtividade do TJCE como sendo o pior do Brasil, mas não se referindo ao lugar do tribunal no IPC-Jus, e sim ao IPM.

Para contornar os desconfortos institucionais a que os indicadores de produtividade comparada submetem os tribunais, os atores do Judiciário também agem criativamente, assim como a mídia, principalmente no que diz respeito a criar outras posiçóes favoráveis a partir de recombinaçóes. Essa estratégia de reposicionamento se desdobra em outras duas, que são: i) projetar interpretação de que determinada posição é boa; e ii) destacar que outros indicadores são de igual importância para qualificar o que os atores são na visão deles próprios. Esses desdobramentos podem ser complementares também, a depender da situação na qual se encontram.

Ao que parece, a estratégia de significar o pior pelo jornal Diário do Nordeste, em 2018, foi também adotada pelos atores do TJCE para destacar o lugar do tribunal no ranking nacional, em 2019: "o TJCE avançou no Índice de Produtividade dos Magistrados (IPM). (...) Com essa estatística, a Corte cearense subiu sete posiçóes, entre os 27 Tribunais de Justiça do Brasil, ocupando atualmente a $20^{\underline{a}}$ colocação". Em entrevista para o site, o presidente do tribunal destacou: "Crescemos sete posiçóes, apesar de sermos o de menor orçamento do país. O crescimento ocorreu mesmo com redução no número de julgadores, que passou de 445 para 402” (TJCE, 2019, grifo nosso).

Ainda como reforço, os atores destacaram a subida em sete posiçóes comparando tais indicadores com outros tribunais: "O TJ do Ceará (médio porte) continua tendo o menor orçamento por habitante $(\mathrm{R} \$ 135,2)$ do país. Roraima, que é de pequeno porte, apresenta $\mathrm{R} \$ 397,3$. A média nacional é de $\mathrm{R} \$ 256,8$, enquanto o [Tribunal de Justiça do Distrito Federal e dos Territórios] TJDFT $(\mathrm{R} \$ 921,8)$ tem o maior, ou seja, quase sete vezes do que o TJCE” (TJCE, 2019, grifo nosso).

Esse é um caso no qual talvez não fosse estratégico para nenhum dos atores (mídia e tribunal) problematizarem o próprio IPC-Jus, já que, em 2018, apesar da posiçáo relativamente baixa do TJCE no ranking do porte a que pertence - inclusive, a mesma alcançada em 2017 -, seria mais relevante destacar o IPM; e já que, em 2019, o tribunal subiu apenas uma posição no IPC-Jus e sete no IPM, seria mais vitorioso destacar este último como símbolo de produtividade.

Há também o caso do Tribunal de Justiça do Estado do Amazonas (TJAM). Em 2018, o TJAM ocupou o último lugar no IPC-Jus na sua categoria; em 2019, subiu quatro posiçóes. No entanto, em 2019, outros resultados foram mais interessantes ressaltar como indicadores de produtividade do tribunal, e não se incluía o de magistrados. Com o título da reportagem Tribunal de Justiça do Amazonas é Destaque Nacional no Relatório Justiça em Números, na página institucional do TJ destacava-se que, "pela primeira vez, é o Tribunal Estadual brasileiro com o maior índice de produtividade entre servidores e o que possui a menor taxa de congestionamento processual em execução fiscal no país" (TJAM, 2019). Com esses dados, o presidente do TJ afirmou que "O TJAM é um dos mais produtivos do Brasil, mesmo estando apenas com 50\% de sua capacidade de servidores" (op. cit.).

Há muitos outros casos. No entanto, a partir das articulaçôes teórico-conceituais desenvolvidas anteriormente, percebemos (conforme representado na figura 1) que a diversidade de enquadramento de reposicionamento é possível porque os atores tiveram a habilidade de recombinar os elementos que 
constituem o IPC-Jus, entre outras estatísticas presentes no relatório, para projetarem reinterpretaçóes do que significa ser um tribunal produtivo. Mais especificamente, a criação de novas interpretaçóes, a partir de novas recombinaçóes dos elementos estatísticos em questão, tornou-se viável porque os atores perceberam a diversidade de características interna do IPC-Jus e a possibilidade de usar outras estatísticas que não estão diretamente ligadas ao IPC-Jus; e conseguiram recombinar os elementos constituintes dessas estatísticas, de modo que se tornasse possível criar outra posição, com projeçôes mais favoráveis.

A ação criativa dos atores do TJCE e do TJAM tornou outro aspecto evidente: a depender da situação na qual se encontram os atores e de suas habilidades de enquadramento, diferentes posiçóes e interpretaçôes favoráveis podem ser criadas.

\section{FIGURA 1}

Esquema de enquadramento de reposicionamento para a produção de interpretações favoráveis

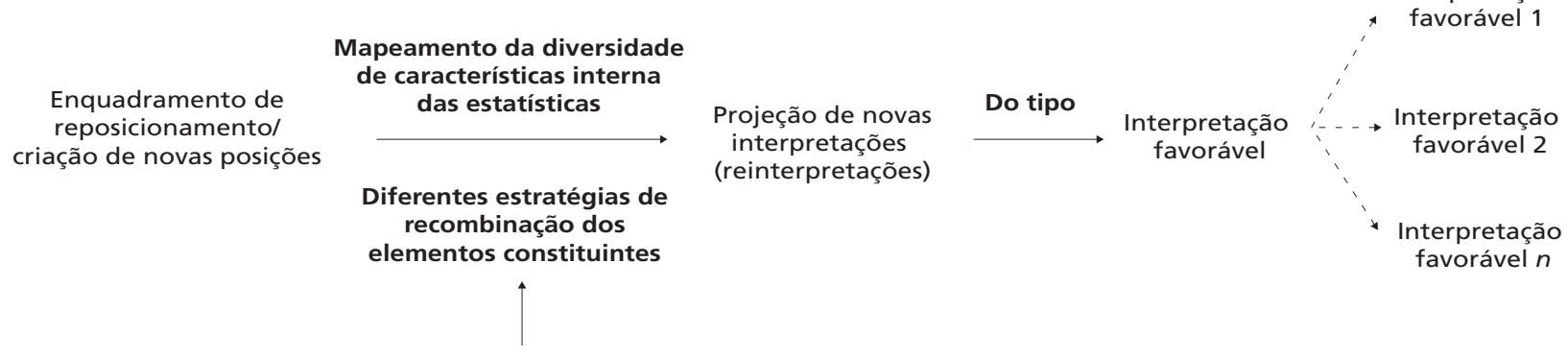

Mecanismos socialmente habilidosos

Elaboração das autoras.

Localizamos, nos casos do TJCE e TJAM, as diferentes maneiras de enquadramento de reposicionamento para a produção de diferentes interpretaçóes favoráveis (quadro 1), entre as quais estão: i) projetar interpretação de que determinada posição é boa - "TJCE é um bom tribunal”; ii) destacar que outros indicadores são de igual importância para qualificar o que os atores são na visão deles próprios - "TJAM é um dos melhores tribunais do Brasil”; e há um terceiro, que é uma espécie de intersecção dos dois primeiros, iii) projetar interpretação de que determinada posição é boa, mobilizando outros indicadores considerados mais qualificados na visão deles próprios - "TJCE é um bom tribunal, podendo ser considerado até melhor que outros tribunais julgados melhores pelo IPC-Jus".

Um aspecto que pode ser percebido, a partir dos detalhes destacados no quadro 1, é que os diferentes enquadramentos de reposicionamento são provenientes de combinaçóes que juntam elementos "positivos" a elementos "negativos" para tornar as trilhas de interpretaçóes favoráveis sobre o que seja a produtividade judicial passíveis de confiabilidade, que é um indicador da busca dos atores pela coerência e contextualização das projeçóes que empreendem de si. 


\section{QUADRO 1}

Estratégias de enquadramento de reposicionamento do TJCE e do TJAM

\begin{tabular}{|c|c|c|}
\hline \multicolumn{3}{|c|}{ TJCE 1 - TJCE é um bom tribunal. } \\
\hline \multicolumn{3}{|c|}{ Interpretação favorável 1: projetar interpretação de que determinada posição é boa. } \\
\hline Reposicionamento & Mapeamento da diversidade & Estratégia de recombinação \\
\hline $\begin{array}{l}\text { O IPM é mais importante que o IPC-Jus, } \\
\text { porque mostra o quanto subimos, apesar } \\
\text { de perdas no quadro de julgadores e } \\
\text { limitações orçamentárias. }\end{array}$ & $\begin{array}{l}\text { a) o IPM é indicador de produtividade também } \\
\text { próximo ao IPC-Jus, já que o compõe; } \\
\text { b) há o ranking de orçamento dos tribunais, uma } \\
\text { variável importante para o cálculo do IPC-Jus; e } \\
\text { c) o número de juízes/julgadores é variável que } \\
\text { compõe o IPM que, por sua vez, compõe o IPC-Jus. }\end{array}$ & $\begin{array}{l}\text { Subir sete posições no IPM + ter o menor } \\
\text { orçamento do país por habitante + possuir } \\
\text { menos juízes em seu quadro de julgadores = } \\
\text { TJCE é um bom tribunal. }\end{array}$ \\
\hline \multicolumn{3}{|c|}{ TJAM - TJAM é um dos melhores tribunais do Brasil. } \\
\hline \multicolumn{3}{|c|}{ Interpretação favorável 2: destacar que outros indicadores são de igual importância para qualificar o que os atores são na visão deles próprios. } \\
\hline Reposicionamento & Mapeamento & Estratégia de recombinação \\
\hline $\begin{array}{l}\text { O IPS e a TC de execução fiscal nos qualificam } \\
\text { como o melhor tribunal em produtividade do } \\
\text { Brasil, apesar de eles não serem o IPC-Jus. }\end{array}$ & $\begin{array}{l}\text { a) o IPS é indicador de produtividade e é variável } \\
\text { que constitui o IPC-Jus; } \\
\text { b) número ideal de servidores para dar conta das } \\
\text { demandas do tribunal; e } \\
\text { c) a TC de execução fiscal é um ranking constante } \\
\text { no relatório. }\end{array}$ & $\begin{array}{l}\text { Ter os servidores mais produtivos em } \\
\text { comparação a todos os tribunais, inclusive } \\
\text { em comparação aos bem posicionados no } \\
\text { IPC-Jus + operar contendo apenas a metade } \\
\text { do número ideal de servidores para responder } \\
\text { à demanda do tribunal + ter o menor } \\
\text { congestionamento de execução fiscal, quando } \\
\text { comparado a todos os tribunais, inclusive } \\
\text { em comparação aos bem posicionados no } \\
\text { IPC-Jus = TJAM é um dos melhores tribunais } \\
\text { do Brasil. }\end{array}$ \\
\hline \multicolumn{3}{|c|}{ TJCE 2 - TJCE é um bom tribunal, podendo ser considerado até melhor que outros tribunais julgados melhores pelo IPC-Jus. } \\
\hline \multicolumn{3}{|c|}{$\begin{array}{l}\text { Interpretação favorável 3: projetar interpretação de que determinada posição é boa, mobilizando outros } \\
\text { indicadores considerados mais qualificados na visão deles próprios. }\end{array}$} \\
\hline Reposicionamento & Mapeamento & Estratégia de recombinação \\
\hline $\begin{array}{l}\text { O IPM é mais importante que o IPC-Jus, } \\
\text { porque mostra o quanto produzimos, } \\
\text { apesar de perdas no quadro de julgadores e } \\
\text { limitações orçamentárias que outros tribunais } \\
\text { considerados os melhores pelo IPC-Jus, quando } \\
\text { comparado ao nosso caso, não têm. }\end{array}$ & $\begin{array}{l}\text { a) o IPM é indicador de produtividade também } \\
\text { próximo ao IPC-Jus, já que o compõe; } \\
\text { b) há o ranking de orçamento dos tribunais, uma } \\
\text { variável importante para o cálculo do IPC-Jus; e } \\
\text { c) o número de juízes/julgadores é variável que } \\
\text { compõe o IPM que, por sua vez, compõe o IPC-Jus. }\end{array}$ & $\begin{array}{l}\text { Subir sete posições no IPM + ter o menor } \\
\text { orçamento por habitante do país + } \\
\text { oçamento por habitante de tribunais com } \\
\text { elevada posição no IPC-Jus = TJCE é um bom } \\
\text { tribunal, podendo ser considerado até melhor } \\
\text { que outros tribunais julgados melhores pelo } \\
\text { IPC-Jus. }\end{array}$ \\
\hline
\end{tabular}

Elaboração das autoras.

Obs.: TJCE 1 - situação argumentativa 1; TJCE 2 - situação argumentativa 2.

\section{CONSIDERAÇÕES FINAIS}

Quando o presidente da Associação dos Magistrados da Bahia construiu a explicação favorável de que, apesar da colocação desfavorável no IPC-Jus, "O juiz [baiano] mata um leão por dia” (Nascimento, 2016), ele a fez a partir de uma ação estrategicamente simbólica que os atores empreendem para projetarem novas interpretaçóes de si. Explorando outros casos semelhantes a este, identificamos que, em contextos nos quais os atores estão em posições desfavoráveis em rankings estatísticos rankings considerados, inclusive, controversos na visão deles -, eles precisam projetar interpretaçóes favoráveis de si a partir dos enquadres que lhes desfavoreceram. Essa habilidade, que consideramos socialmente estratégica, depende de eles perceberem a diversidade de características que constituem tais enquadres desfavoráveis e da capacidade de saber criar recombinaçóes, para projetarem novas trilhas interpretativas de si que lhes sejam mais apropriadas. 
Nos casos trabalhados identificamos também que, a depender da situação na qual se encontram os atores e de suas habilidades de enquadramento, diferentes posiçóes e interpretaçóes favoráveis podem ser criadas; e, mesmo que tomem diferenciaçóes, eles sempre o fazem respeitando a coerência contextual que a nova projeção favorável precisa ter. Entre essas diferentes diferenciaçóes de enquadres de reposicionamento estavam: i) projetar interpretação de que determinada posição é boa; ii) destacar que outros indicadores são de igual importância para qualificar o que os atores são na visão deles; e iii) projetar interpretação de que determinada posição é boa, mobilizando outros indicadores considerados mais qualificados na visão deles próprios.

A despeito de toda essa mobilização criativa dos atores, fica uma curiosidade: por que evidências estatísticas que necessariamente criam o melhor e o pior se institucionalizam ao longo do tempo?

\section{REFERÊNCIAS}

BERK, G.; GALVAN, D. C. Processes of creative syncretism: experiential origins of institutional order and change. In: BERK, G.; GALVAN, D. C.; HATTAM, V. (Org.). Political creativity: reconfiguring order and change. Philadelphia: University of Philadelphia Press, 2013. p. 29-54.

BEYER, J. M. Research utilization: bridging a cultural gap between communities. Journal of Management Inquiry, v. 6, n. 1, p. 17-22, 1997.

CNJ - CONSELHO NACIONAL DE JUSTIÇA. Relatório Justiça em Números: 2013. Brasília: CNJ, 2013.

Relatório Justiça em Números: 2019. Brasília: CNJ, 2019.

ENTMAN, R. M. Framing: toward a clarification of a fractured paradigm. Journal of Communication, v. 43, n. 4, p. 51-58, 1993.

FLIGSTEIN, N. Social skill and the theory of fields. Sociological Theory, v. 19, n. 2, p. 105-125, 2001.

HAGGERTY, K. D. The politics of statistics: variations on a theme. The Canadian Journal of Sociology, v. 27, n. 1, p. 89-105, 2002.

JORDÁ, P.; CASCAJO, R.; MONZÓN, A. Analysis of the technical efficiency of urban bus services in Spain based on SBM models. ISRN Civil Engineering, v. 12, p. 1-13, 2012.

LATOUR, B. Science in action: how to follow scientists and engineers through society. Cambridge, Mass.: Harvard University Press, 1987.

MENDONÇA, R. F.; SIMÕES, P. G. Enquadramento: diferentes operacionalizaçôes analíticas de um conceito. Revista Brasileira de Ciências Sociais, v. 27, n. 79, p. 187-201, 2012.

NASCIMENTO, G. TJBA é o 7o pior em ranking da CNJ: juiz culpa demandas de estado e município. Metro 1, 2016.

PINHEIRO, M. M. S. Políticas Públicas Baseadas em Evidências (PPBEs): delimitando o problema conceitual. Rio de Janeiro: Ipea, abr. 2019. p. 1-42. (Texto para Discussão, n. 2554). 
SILVA, M. K.; COTANDA, F. C.; PEREIRA, M. M. Interpretação e ação coletiva: o "enquadramento interpretativo" no estudo de movimentos sociais. Revista de Sociologia e Política, v. 25, n. 61, p. 143-164, mar. 2017.

TJAM - TRIBUNAL DE JUSTIÇA DO ESTADO DO AMAZONAS. Tribunal de Justiça do Amazonas é destaque nacional no Relatório Justiça em Números. [s.l]: TJAM, 2019.

TJCE - TRIBUNAL DE JUSTIÇA DO ESTADO DO CEARÁ. TJCE sobe sete posiçóes no ranking do Conselho Nacional de Justiça. [s.l.]: TJCE, 2019.

VESELÝ, A.; OCHRANA, F.; NEKOLA, M. When evidence is not taken for granted: the use and perception of "evidence" in the Czech Republic Ministries. The NISPAcee Journal of Public Administration and Policy, v. 11, n. 2, p. 219-234, 2018.

\section{SITES CONSULTADOS}

Conselho Nacional de Justiça (CNJ). Disponível em: <https://www.cnj.jus.br/corregedor-nacionalabre-trabalho-de-inspecao-no-tjam/>.

Diário do Nordeste. Disponível em: <https://diariodonordeste.verdesmares.com.br/editorias/metro/ tjce-tem-pior-indice-de produtividade-do-pais-1.1815548>.

G1. Disponível em: <https://g1.globo.com/pi/piaui/noticia/piaui-tem-terceiro-pior-desempenhoentre-os-tribunais-estaduais-no-brasil-diz-cnj.ghtml>.

Jornal da Paraíba. Disponível em: <http://www.jornaldaparaiba.com.br/politica/magistrados-daparaiba-tem-o-pior-indice-de-produtividade-do-brasil-segundo-cnj.html>.

Jornal da Paraíba. Disponível em: <www.jornaldaparaiba.com.br/vida_urbana/tjpb-tem-3o-pior-indicede-produtividade-entre-os-tribunais-estaduais-pais.html>.

Metro 1. Disponível em: <https://www.metro1.com.br/noticias/bahia/23816,tj-ba-e-o-7o-pior-emranking-da-cnj-juiz-culpa-demandas-de-estado-e-municipio $>$.

Metro 1. Disponível em: <https://www.metro1.com.br/noticias/bahia/23816,tj-ba-e-o-7o-pior-emranking-da-cnj-juiz-culpa-demandas-de-estado-e-municipio $>$.

O POVO. Disponível em: <https://mais.opovo.com.br/jornal/politica/2019/08/28/tjce-deixa-deser-o-pior-em-produtividade-do-brasil.html>.

Tribuna do Norte. Disponível em: <www.tribunadonorte.com.br/noticia/tjrn-a-o-3ao-tribunalmais-caro-e-o-3ao-menos-eficiente-do-paa-s/458462>.

Tribunal de Justiça do Estado do Amazonas (TJAM). Disponível em: <https://www.tjam.jus.br/ index.php/menu/sala-de-imprensa/1842-tribunal-de-justica-do-amazonas-e-destaque-nacional-norelatorio-justica-em-numeros $>$.

Tribunal de Justiça do Estado do Ceará (TJCE). Disponível em: <https:/www.tjce.jus.br/noticias/ tjce-sobe-sete-posicoes-no-ranking-do-conselho-nacional-de-justica/ $>$. 